\title{
THE ENVIRONMENT
}

\section{Wayne J. Colberg and John A. Callenbach}

It should be obvious, even to the most casual observer, that man must better understand the environment in which he lives. He must learn to use his resources wisely and intelligently. And this does not imply either a need or recommendation that the use of resources or the application of the latest technology be drastically curtailed.

Advent of new organic pesticides in the early 1940 's truly opened a new era in pest control. For the first time man was partially successful in manipulating his environment insofar as his ability to control insects, weeds, diseases and rodents is concerned.

Pest control has become a real and serious matter that has a direct impact on each and everyone of us. Our society has gained tremendous benefits from the use of pesticides by protecting us and our possessions from the ravages of pests. These chemicals will continue to be used in pest management in spite of the adverse publicity concerning their detrimental effects on the environment.

The great controversy over the use of pesticides comes at a time when most people enjoy the highest standard of living ever known. Much of this can be attributed to the use of pesticides in the production of food and fiber, and disease control.

Pesticidal residues and persistence seem to be the key words in discussing pesticides and the environment. The residue problem will always confront us when we use toxic chemicals having any degree of persistence. However, this problem is being greatly diminished through proper selection and application of pesticides. Persistence of a pesticide is not in itself an undesirable quality, but it can become a problem, especially when it finds its way into non-target areas. Once this happens, a pesticide can become harmful to non-pest plants and animals.

Furthermore, through continual exposure and repeated use some pesticides can accumulate in the environment in amounts that are detectable by precision instruments. There are documented cases

Colberg is professor and extension entomologist and pesticide coordinator, Cooperative Extension Service, and Dr. Callenbach is professor and chairman, Department of Entomology. of excessive pesticide residues in the environment and there have been reported cases of bird and fish kills, and illegal residues in food (above established legal tolerances).

While these cases are exceptions rather than the rule, pesticidal problems associated with the environment are constantly appearing. The public is now demanding that consideration be given to the non-monetary costs in terms of the effects that pesticides may have on people, the environment and the ecological balance of nature. Because of the conspicuous role pesticides play as potential pollutants in the environment, it seems easy to shift the blame to these chemicals as the most important pollutants. This is particularly true when other solutions to the problem are more difficult, and especially when attention to these factors demands less public support.

We must understand that there are potential hazards in the use of pesticides and that improper or careless use can result in adverse effects on man and his environment. Society is continually faced with the task of balancing the good against the bad, and pest control is no exception. There must be some type of benefit-risk equation in determining the justification for the control of pests. Today most decisions regarding pest management have to be judged independently.

But it would certainly be a disservice to society to completely ban the use of pesticides and to accept pestilence as a way of life. Or, adopt in their place some glamorously new but untested method of pest control whose effects on people and the environment are even less understood than the pesticides it replaces. Non-chemical pest control continues to have limited value, but these methods will not take the place of chemicals in the foreseeable future.

We must continually ask ourselves about the environmental pollution problem in the same manner as any other problem: (1) we must have an open mind, (2) we must gather all available facts, (3) we must conduct research to provide additional facts needed to solve some of the major problems, and (4) we must demonstrate a determination to proceed toward such action which will solve the problems of today, tomorrow and the future. 